INTERNATIONAL JOURNAL OF RESEARCHES IN BIOSCIENCES, AGRICULTURE AND TECHNOLOGY (C) VISHWASHANTI MULTIPURPOSE SOCIETY (Global Peace Multipurpose Society) R. No. MH-659/13(N) www.ijrbat.in

\title{
HPLC ANALYSIS OF METHANOLIC EXTRACT OF AREAL PARTS OF LEONOTIS NEPETIFOLIA (L.) R. BR.
}

\author{
Rupali Shirsat ${ }^{1}$, Syed Imran² and Deepak Koche ${ }^{2}$ \\ 1Department of Botany, Shri Dr. R. G. Rathod Arts and Science College, Murtizapur, Dist- Akola (MS) \\ India 444107 \\ 2PG Department of Botany, ShriShivaji College of Arts, Commerce and Science, Akola (MS) India 444001 \\ Email- dipakkoche43@gmail.com
}

\begin{abstract}
:
The HPLC analysis of methanolic extract of areal parts of Leonotis nepetifolia (L.) R. Br. was done. The chromatogram revealed five major peaks. The phytochemical compounds were interpreted on the basis of retention time and identified as of Caffeic acid, Luteolin-7- glucoside, Nepetin-7 glucoside, Homoplantagenin and Ursolic acid. The content of homoplantagenin was found to be highest $(5.5 \square \mathrm{g} / \mathrm{g}$ dry wt. of sample) while that of caffeic acid was least $(0.68 \square \mathrm{g} / \mathrm{g}$ dry wt. of sample). All the identified compounds are medicinally valued and each compound could be used as drug candidate after individual isolation and pharmacological testing.
\end{abstract}

Keywords: Leonotis nepetifolia (L.) R. Br., HPLC, medicinal value.

\section{INTRODUCTION:}

Leonotis nepetifolia (L.) $\mathrm{R}$. Br. is an erect herbaceous plant belonging to family Lamiaceae and native to southern India. The plant is commonly known as "Deepmal" in Marathi. It was observed to use in traditional medicine, mainly the areal part to cure common fever, urinary disorders and skin inflammation (Chaudhary et al., 1993; Bhogaonkar and Deokule, 2002 and Ayyanar and Ignacimuthu, 2005). Traditional medicine is playing vital role in healthcare systems especially in developing countries (WHO, 2002). The preliminary phytochemistry of this plant was explored by many workers (Trivedi et al., 2011 and Gnaneshwari and VenkataRaju, 2012). Some reports also indicate the biological activities possessed by this plant (Nitya et al., 2011 and Sinha, 2012). However, the reports on its detail chemical composition are lacking. The present attempt is to explore its major chemical constituents using HPLC.

\section{METHOD AND MATERIAL:}

The plant material of Leonotis nepetifolia was collected from local agricultural waste lands of Akola (MS). The collected plant material was identified taxonomically using floras (Naik, 1998) and one specimen copy was deposited in Department of Botany, Shri. Shivaji College of Arts, Commerce and Science, Akola (MS). The areal material was shade dried for 10-12 days and powdered. The fine powder was used for further phytochemical analysis.

Chromatographic analysis was performed on Shimadzu make high performance liquid chromatography system, equipped with a diode array detector working in the range of 190-400 nm, a quaternary solvent delivery system, a column temperature controller and an autosampler. Analysis was carried out at $30 \mathrm{oC}$ on a $\mathrm{C} 18$ column (250mm $\times 4.6 \mathrm{~mm}, 5 \square \mathrm{m}$ ). A linear gradient elution of eluents A $(0.5 \%, \mathrm{v} / \mathrm{v}$ aqueous glacial acetic acid) and $B$ (methanol) was used for the separation. The elution programme was optimized and conducted as follows: a linear gradient of $38-42 \% \mathrm{~B}$ with the range of $0.0-14.0 \mathrm{~min}$, a linear gradient of $42-45 \%$ $\mathrm{B}$ with the range of 14.0-17.0 min, a linear gradient of $45-48 \%$ B with the range of $17.0-17.1 \mathrm{~min}$, a linear gradient of $48-50 \%$ B with the range of $17.1-$ $32.0 \mathrm{~min}$ and a linear gradient of $50-85 \% \mathrm{~B}$ with the range of 32.0-45.0 $\mathrm{min}$. This was followed by a 10 min equilibration period prior to the injection of each sample. 
All the samples were milled into powder and ovendried at 50oC until constant weight was reached. $1.0 \mathrm{~g}$ powder of each dried sample was extracted with $20 \mathrm{ml} 70 \%(\mathrm{v} / \mathrm{v})$ aqueous methanol in an ultrasonic bath for $2 \mathrm{~h}$ and then cooled at room temperature. The extract was filtered through glass wool for sample, cleaned up and diluted to $25 \mathrm{ml}$ with $70 \%$ methanol. The sample solution was filtered through a $0.45 \mu \mathrm{m}$ membrane filter prior to HPLC analysis and the injection volume was $5 \mu 1$.

\section{RESULTS AND DISCUSSION}

The HPLC analysis data of $L$. nepetifoliais presented in the table 4.15. The HPLC chromatogram (Fig. 1) of methanolic leaf extract showed five major peaks. The compounds were identified on the basis of retention time. The peaks obtained in the chromatogram were correlated with the peaks of standard reference compounds and detect the most probable compound. After confirmation, the peak area of measured for the calculation of compound present in the given extract. The $L$. nepetifolia methanolic extract showed presence of Caffeic acid, Luteolin-7- glucoside, Nepetin-7 glucoside, Homoplantagenin and Ursolic acid. The table 1 showed the absorption maxima of the compound and content calculated on the basis of peak area. The content of homoplantagenin was found to be highest (5.5 $\square \mathrm{g} / \mathrm{g}$ dry wt. of sample) while that of caffeic acid was least ( $0.68 \square \mathrm{g} / \mathrm{g}$ dry wt. of sample). Secondary methabolites synthesized by plants are of increasing interest for the humans and they provide the medicinal potential to plants and in isolated form could be used as drug candidate after pharmacological investigation. Earlier, Ayanwui et al., (2009), Nitya et al., (2011) and Sinha (2012) reported the anticonvolucent, antimicrobial and would healing potential of $L$. nepetifolia. These activities might be due to individual or synergistic action of the secondary metabolites present in this plant. Among the compounds identified during present study, caffeic acid is a polyphenol and potent antioxidant; Luteolin -7 glucoside and nepetin- 6 glucoside were also polyphenols especial flavonoids with antioxidant potential; homoplantagenin is a flavon with insecticidal activity while ursolic acid is triterpene with antiinflammatory activity. Further these phytochemicals should be isolated separately from the extract and the plant could be use as potent source of these medicinally potential phytochemicals.

Acknowledgement: The authors are grateful to the Principal, Shri. Shivaji College of Arts, Commerce and Science, Akola for providing necessary facilities.

\section{REFERANCE :}

Ayanwuyi, L.O.,Yaro, A.H., Adamu, H.Y.S. 2009. Studies on anticonvulsant activity of methanol capitulum extract of LeonotisnepetifoliaLinn. Nig. Jou. Pharm. Sci.8(1): Pp. 73-79.

Ayyanar, M. and Ignacimuthu, S. 2005. Traditional Knowledge of Kanitribals in Kouthalai of Tirunelveli hills, Tamil Nadu. India. J. Ethnophar.102: Pp. 246-255.

Bhogaokar, P. Y. and Deokule, S. 2002. Some unique ethnomedicinal plants of Korku of Melghat reserve, Maharashtra.Ethnobotany, 12 (1-2): Pp. 16-19.

Choudhary, B. C., Biswal, A. K. and Sabudhi, S. A. 1993. Enumeration of some potential medicinal plants in the District of Cuttak (Orissa).Bioscience Res. Bull.2(1-2):Pp. 11-16.

Kamalam, M., Saraswathi, C. and Umadevi, U. 2013.Evaluation of Leonotisnepetaefolia for its phytochemical and heavy metal analysis. Int. J. Pharm. Sci. Res. 4(12): Pp. 4591-4596.

Naik, V. N.1998. Flora of Marathwada, AmrutPrakashan, Aurangabad (MS)

Nithya, V., Brinda, P. and Anand, K.V. 2011. Wound healing activity of Leonotisnepetifolia (L) R.BR, in wistar albino rats. Asian J. Pharm.Clinical Res. 4(2): Pp. 23-26.

Sinhasankar Narayan 2012. Antibacterial potential of crude methanolic extract of Leonotisnepetifolia (L) R.BR.Inter.Res.J. Pharm. 3(2): Pp. 277-278.

Trivedi, A., Sethiya,N. K., and Misha, S.H. 2011. Preliminaypharmacognostic and phytochemcial analysis of "Granthika" (Leonotisnepetifolia): An Ayurvedic herb. Indian Journal of Traditional knowledge 10 (4): 682-688. 
Fig. 1 : HPLC Chromatogram of Leonotisnepatifolia leaf powder extract:

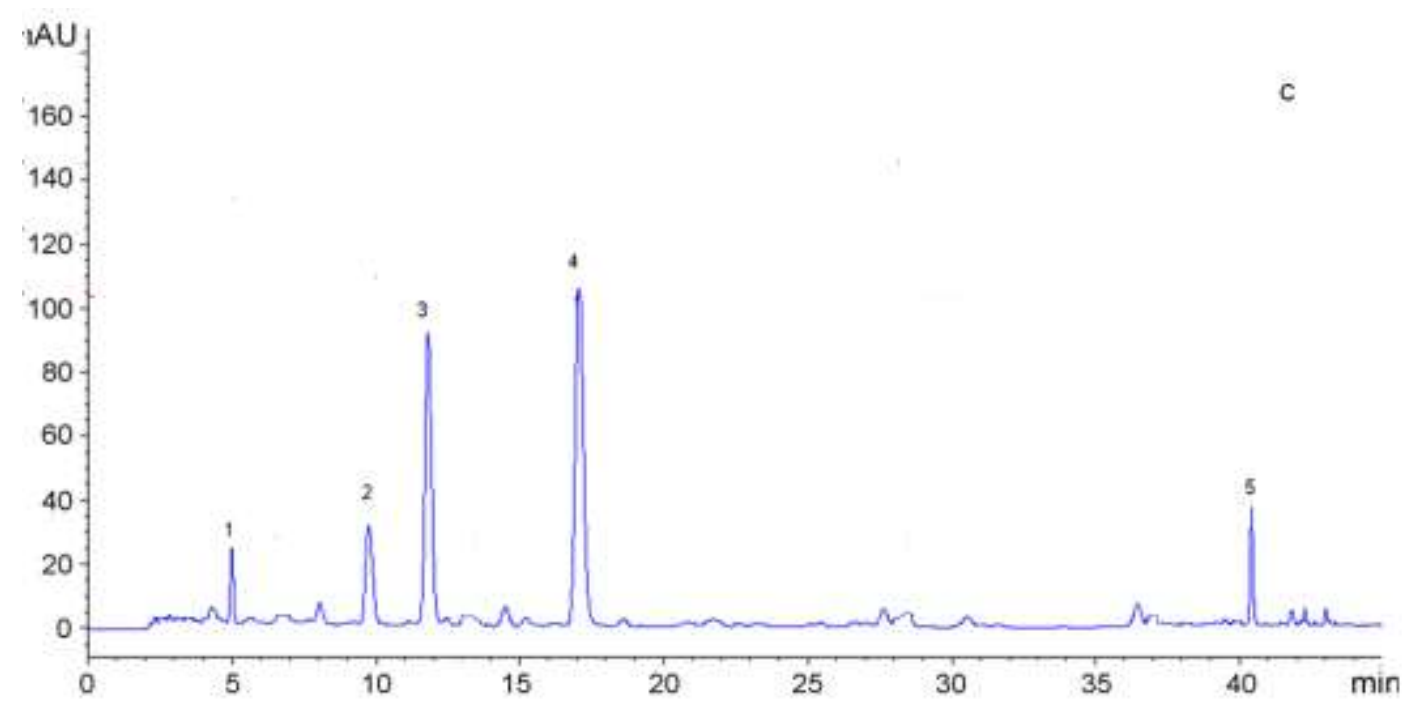

Note: The peaks are identified as: 1- Caffeic acid, 2- Luteolin-7- glucoside,3- Nepetin-7 glucoside, 4Homoplantagenin, and 5- Ursolic acid

\begin{tabular}{|c|c|c|c|}
\hline \multicolumn{4}{|c|}{ Table 1:- HPLC analysis of methanolic extract of L. nepetifolia } \\
\hline Sr. no. & Compound in the sample & $\begin{array}{c}\text { Retention time } \\
\text { RT (min) }\end{array}$ & $\begin{array}{c}\text { Content } \\
\text { ( } \boldsymbol{\mu g} / \mathbf{g}) \text { dry } \\
\text { wt. of sample }\end{array}$ \\
\hline 1 & Caffeic acid & 5.18 & 0.68 \\
\hline 2 & Luteolin -7 glucoside & 11.2 & 1.20 \\
\hline 3 & Nepetin-7 glucoside & 13.5 & 2.80 \\
\hline 4 & Homoplantagenin & 17.5 & 5.50 \\
\hline 5 & Ursolic acid & 41.9 & 0.85 \\
\hline
\end{tabular}

